\title{
Changes in Coronary Resistance Related to the Stages of the Female Life Cycle
}

\author{
Shinji Fukuhara; Shonosuke Matsushita, MD*; Yuzuru Sakakibara, MD*
}

\begin{abstract}
Backgrounds Estrogen is known to dilate the coronary vascular system mainly through nitric oxide (NO) release. However, it has not been determined whether or not this effect occurs equally throughout all stages of the female life cycle. We examined the changes in coronary flow properties in adolescent, adult and ovariectomized (OVX) female rats using the endothelial NO synthetase blocker, L-N (omega) nitroarginine (L-NNA).

Methods and Results Female rats were divided into 3 groups: adolescent (13 weeks, $n=6)$, adult (19 weeks, $\mathrm{n}=8$ ) and OVX (20 weeks, $\mathrm{n}=7,12$ weeks after oophorectomy). Coronary effluent was measured using the Langendorff non-working heart model before and $15 \mathrm{~min}$ after the use of L-NNA. In OVX rats, coronary effluent was significantly decreased in comparison with adolescent and adult rats (adolescent vs OVX: $\mathrm{p}<0.001$; adult vs OVX: $\mathrm{p}<0.05$ ). After treatment with L-NNA, coronary effluent was significantly higher in the adolescent group compared with the adult and OVX groups (adolescent vs adult: $\mathrm{p}<0.01$; adolescent vs OVX: $\mathrm{p}<0.0005$ ).

Conclusions Oophorectomy brought about an increase in coronary vascular resistance. L-NNA exacerbated coronary vascular resistance in relation to maturation. It is suggested that the effect of estrogen on vascular dilatation in adolescents is largely dependent on a non-NO pathway, whereas adults are largely dependent on an NO pathway. (Circ J 2006; 70: 478-481)
\end{abstract}

Key Words: Coronary circulation; eNOS; Estrogen; Female; Maturation

C oronary artery disease $(\mathrm{CAD})$ is one of the most prevalent types of heart disease in the industrialized world! The incidence of myocardial infarction in women is lower than it is in men until they reach their mid-forties according to the Framingham Study? The incidence of CAD in women increases after the age of 55 and it exceeds the incidence of CAD in men at over 75 years. Moreover, in regard to female hormones, the incidence of cardiovascular disease is greater in the postmenopausal period than in the premenopausal period ${ }^{3-5}$ It is assumed that female hormones have protective effect in regard to CAD. It has already been reported that estrogen shows a number of beneficial effects on the cardiovascular system?-13 Estrogen dilates coronary vessels by up-regulating endothelial nitric oxide synthetase (eNOS) by means of a genomic effect 14,15 eNOS has an essential role on coronary vasodilation; for example, a mutation on the eNOS gene is associated with coronary vasospasm. ${ }^{16}$ Coronary vasospasm occurs even in female adolescents with a suspected abnormality of the eNOS gene $!^{7}$ However, the role of eNOS on arterial dilatation in female growth and aging remains uncertain. Furthermore, it has been reported in pigs that the dilation of the cerebral artery is dependent on prostanoid in infancy, whereas it becomes more dependent on nitric oxide (NO) in adulthood, which means there is a kind of age-dependency for vasodilators ${ }^{18}$ Therefore, the present study was designed to investigate the role of eNOS on coronary circulation in the various stages of the female life cycle using L-N (omega) nitroarginine (L-NNA; an

(Received May 30, 2005; revised manuscript received January 10, 2006; accepted January 16, 2006)

School of Medicine, *Department of Cardiovascular Surgery, University of Tsukuba, Tsukuba, Japan

Mailing address: Shonosuke Matsushita, MD, Department of Cardiovascular Surgery, University of Tsukuba, 1-1-1 Tenoudai, Tsukuba 305-8573, Japan inhibitor of eNOS).

\section{Methods}

The Committee on Animal Research at the University of Tsukuba approved the experimental protocols. The rats were cared for in accordance with the Guiding Principles for the Care and Use of Animals based on the Helsinki Declaration of 1964.

\section{Animal Preparation and Langendorff Perfusion}

Female Wistar-Imamichi rats (Institute of Animal Reproduction, Ibaraki, Japan) were used. Rats were divided into 3 groups: adolescent group (13 weeks, body weight $=$ $250-300 \mathrm{~g}, \mathrm{n}=6)$, adult group ( 19 weeks, body weight $=280$ $320 \mathrm{~g}, \mathrm{n}=8$ ) and ovariectomized (OVX) group (20 weeks, body weight $=340-410 \mathrm{~g}, \mathrm{n}=7 ; 12$ weeks after oophorectomy). An age of 13 weeks in Wistar-Imamichi rats was regarded as juvenile because their body weights were increasing and the estradiol cycle is established in 100\% of the population. An age of 19 weeks was regarded as adult due to attainment maximum ovarian mass, as found in the literature 19 Because of the rapid change of estradiol cycle in female rat, the serum estrogen concentration of non-OVX rats was considered to correspond the average between the proestrus and estrus stages 20 After anesthetization by diethyl ether inhalation, their hearts were excised and prepared for the Langendorff apparatus. The hearts were perfused with a modified Krebs-Henseleit $(\mathrm{KH})$ solution, which contained $124 \mathrm{mmol} / \mathrm{L} \mathrm{NaCl}, 6.8 \mathrm{mmol} / \mathrm{L} \mathrm{KCl}$, $1.3 \mathrm{mmol} / \mathrm{L} \mathrm{MgSO} 4,1.1 \mathrm{mmol} / \mathrm{L} \mathrm{KH}_{2} \mathrm{PO} 4,2.5 \mathrm{mmol} / \mathrm{L}$ $\mathrm{CaCl}_{2}, 26 \mathrm{mmol} / \mathrm{L} \mathrm{NaHCO} 3$ and $5.6 \mathrm{mmol} / \mathrm{L}$ glucose. This was undertaken under a coronary pressure of $66 \mathrm{mmHg}$ and $460 \pm 11 \mathrm{mmHg}$ in oxygen tension. The hearts were kept at $37^{\circ} \mathrm{C}$ and stabilized for $20 \mathrm{~min}$ after the initial perfusion to avoid the effect of primary ischemia. Then, coronary flow 
Perfusates

KH solution

KH solution +

L-NNA $(100 \mu \mathrm{mol} / \mathrm{L})$

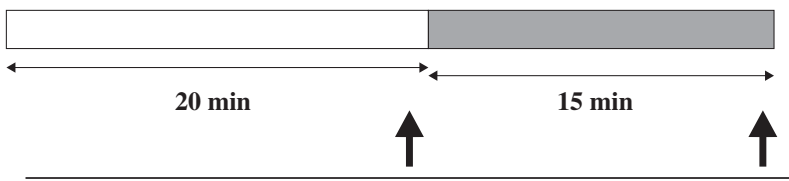

\begin{tabular}{lcc}
\hline & Series 1 & Series 2 \\
\hline $\begin{array}{l}\text { Coronary Effluent } \\
\text { Measurement }\end{array}$ & $\bigcirc$ & $\bigcirc$ \\
\hline
\end{tabular}

( $\mathrm{ml} / \mathrm{min} / \mathrm{g}$ heart weight)

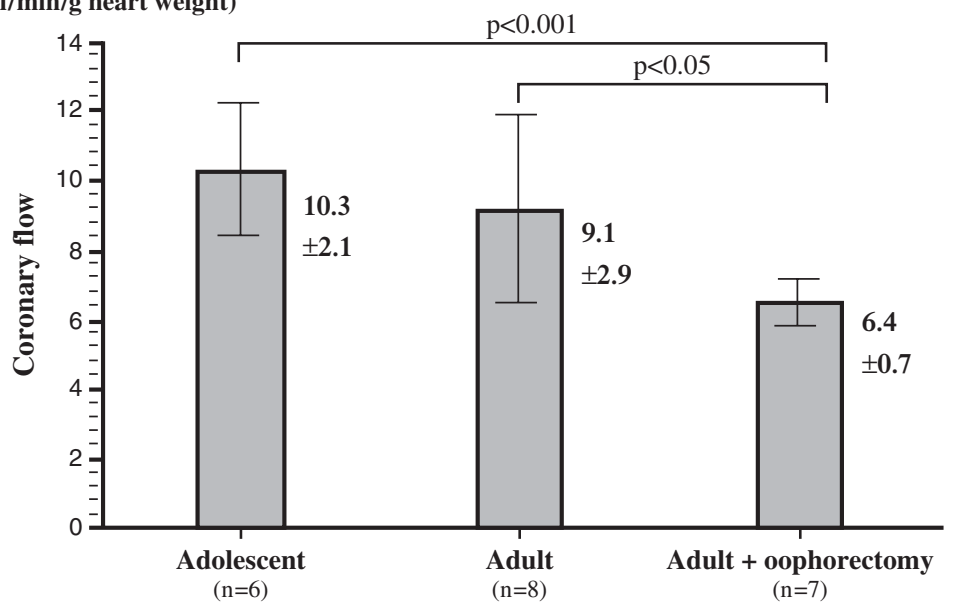

( $\mathrm{ml} / \mathrm{min} / \mathrm{g}$ heart weight $)$

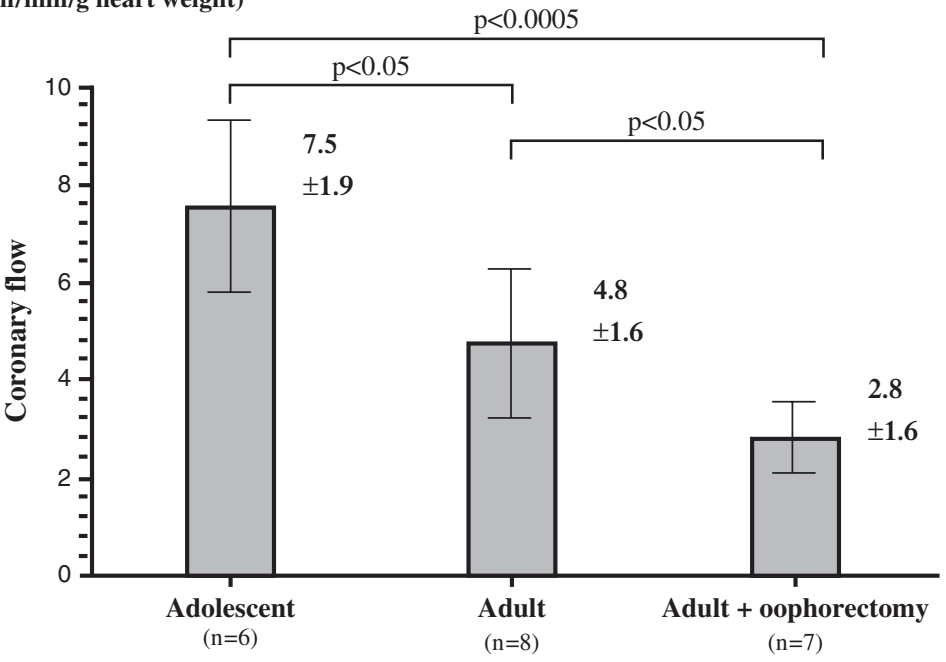

Fig 1. Experimental protocol. Coronary effluent was measured $20 \mathrm{~min}$ after perfusion of $\mathrm{KH}$ solution (Series 1) and $15 \mathrm{~min}$ after the perfusion of L-NNA. $\mathrm{KH}$, Krebs-Henseleit; L-NNA, L-N(omega) nitroarginine.

Fig 2. Comparison of initial coronary effluent in 3 different female groups. Coronary flow of initial perfusion in different female rat groups indicated that oophorectomy was the causative factor exaggerating coronary vascular resistance.

Fig 3. Comparison of actual coronary effluent after 15 min use of L-NNA. Coronary effluent significantly decreased in the order of adolescent rats, adult rats and oophorectomy rats after the use of L-NNA. The flow in ovariectomized rats was affected by both oophorectomy and endothelial nitrite oxygen synthetase inhibition. L-NNA, L-N(omega) nitroarginine.

$(\mathrm{ml} / \mathrm{min})$ was continuously measured every $60 \mathrm{~s}$.

\section{Experimental Protocols (Fig 1)}

Series 1 Coronary effluent was measured under stable conditions confirmed after $20 \mathrm{~min}$ of Langendorff perfusion.

Series 2 At $15 \mathrm{~min}$ after the initiation $100 \mu \mathrm{mol} / \mathrm{L}$ of the eNOS inhibitor L-NNA, coronary effluent was measured.

\section{Statistics}

All variables were expressed as mean \pm SD. All groups were analyzed for statistics using a Student's unpaired t-test with Bonferroni correction. A difference of $\mathrm{p}<0.05$ was considered significant.

\section{Results}

Series 1

Coronary flow measurements were performed under conditions of acute estrogen withdrawal because the $\mathrm{KH}$ solution did not contain estrogen. In the OVX group, coronary effluent was significantly decreased in comparison with the adolescent and adult groups (adolescent: 10.3 \pm $2.1 \mathrm{ml}$; Adult: $9.1 \pm 2.9 \mathrm{ml}$; OVX: $6.4 \pm 0.7 \mathrm{ml}$, respectively; 

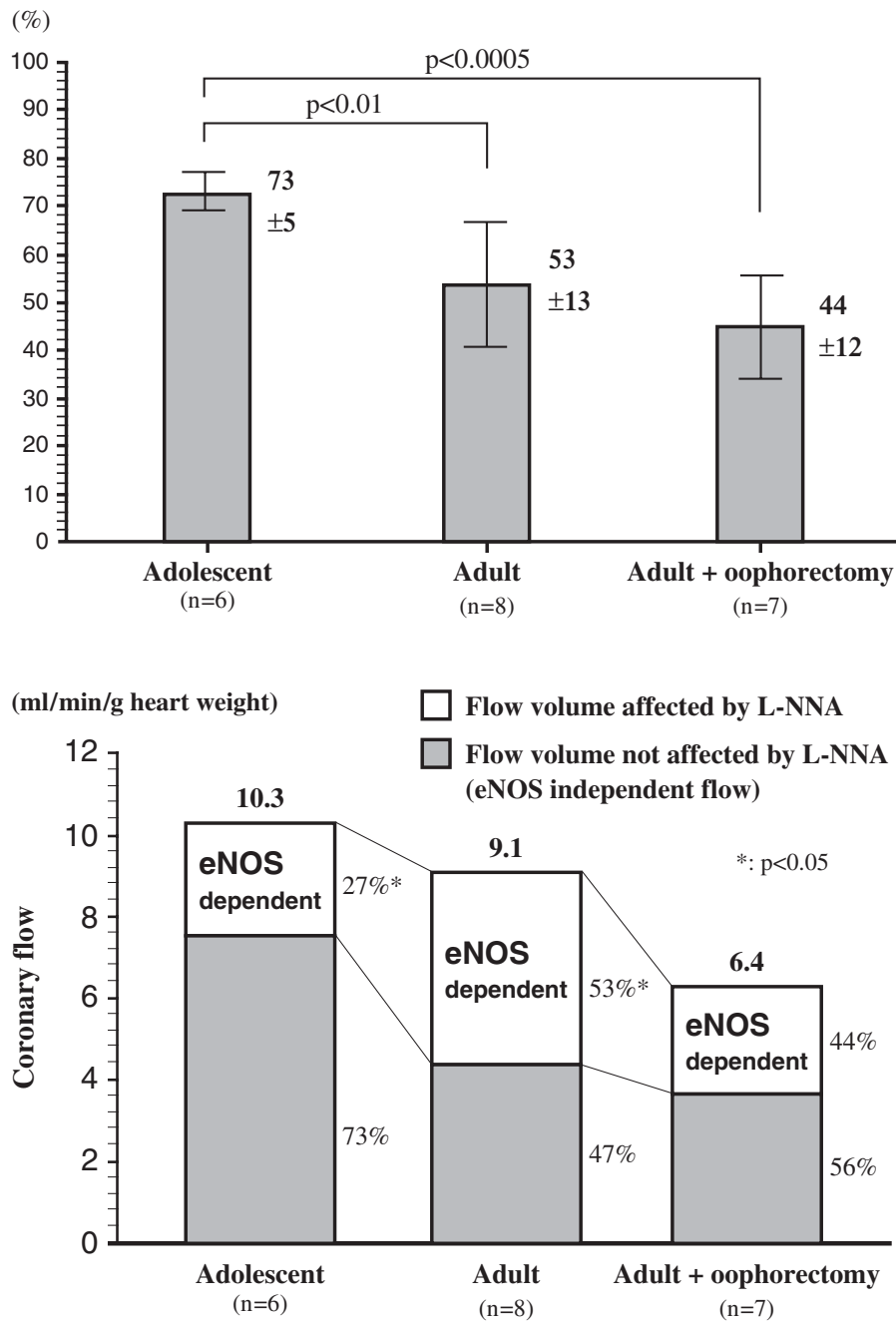

Fig 4. Coronary effluent after the use of L-NNA (represented as percentage from pre L-NNA treatment). When expressed as percentage, the reduction of coronary effluent was different with age. The flow in adolescent rats was significantly higher than in adult rats, regardless of the presence of ovarium, after the use of L-NNA, but there was no significant difference between adult rats. L-NNA, L-N(omega) nitroarginine.
Fig 5. Flow volume of eNOS dependency at initial flow. eNOS dependent flow increased with maturation from $27 \%$ to $53 \%(\mathrm{p}<0.05)$. The percentage of eNOS dependent flow of oophorectomy rats was not significantly different regardless of the presence or absence of the ovarium. eNOS, endothelial nitrite oxygen synthetase; L-NNA, L-N(omega) nitroarginine.
ADOLESCENT vs OVX: $\mathrm{p}<0.001$; adult vs OVX: $\mathrm{p}<0.05)$. Oophorectomy brought about a significant increase in coronary vasoconstriction as compared with the other 2 groups. There was no significant difference between age groups with intact ovarium (Fig 2).

\section{Series 2}

After the use of L-NNA, coronary effluent significantly decreased in of young female rats (adolescent group; $7.5 \pm 19 \mathrm{ml} / \mathrm{min}$ ), mature female rats (group adult; $4.8 \pm$ $1.6 \mathrm{ml} / \mathrm{min}$ ) and OVX rats $(2.8 \pm 1.6 \mathrm{ml} / \mathrm{min}$ ) (adolescent vs adult: $\mathrm{p}<0.05$; adult vs OVX: $\mathrm{p}<0.05$; adolescent vs adult: $\mathrm{p}<0.0005$, respectively, Fig 3 ). When the results were expressed as percentages from pre-treatment of L-NNA, the coronary flow of young female rats was significantly preserved as compared to the adult and OVX groups (adolescent: $73 \pm 5 \%$; adult; $53 \pm 13 \%$; OVX; 45 $\pm 12 \%$, respectively; adolescent vs adult: $\mathrm{p}<0.01$; adolescent vs OVX; $\mathrm{p}<0.0005$, Fig 4).

\section{Discussion}

It is known that estrogen has 2 mechanisms in the relaxing of blood vessels. One is a genomic effect (chronic effect) and the other is a non-genomic effect (acute effect). The genomic effect of estrogen on eNOS is the enhancement of eNOS expression in vascular endothelial cells through binding to estrogen receptors (ER). The nongenomic effect of estrogen on eNOS is the activation of eNOS and the increase of NO production by binding ER onto the vascular endothelial cell membrane? ${ }^{21}$ Another non-genomic effect of estrogen on vasodilation includes a direct effect of vascularizing smooth muscle cells with prostacyclin (PGI2) and endothelium derived hyperpolarizing factor ${ }^{21}$

As seen in the results of the present study, coronary flow in OVX rats significantly decreased compared with nonOVX adult rats and adolescent rats. It is indicated that oophorectomy (a 3 month absence of ovarian function) brought about coronary vasoconstriction due to the reduction of eNOS expression (genomic effect). In contrast, the effects of L-NNA on vascular tone were less significant in young female rats than in mature female rats, regardless of the presence or absence of the ovarium. This indicated that vasodilation is more dependent on eNOS in adult rats than in adolescent rats. Oophorectomy decreased the eNOS dependent flow rather than the eNOS non-dependent flow (Fig 5).

It has recently been noted that the role of vasoactive agents does not have a constant effect throughout life 18,22,23 The cerebral arterial tone is regulated differently in neonates and adults. Cerebral arterial dilatation in newborn piglets is entirely prostanoid dependent, whereas it requires both NO and prostanoids in juveniles ${ }^{18}$ Vasodilatation in newborns 
is $\mathrm{NO}$ independent, but $\mathrm{NO}$ becomes more important for the regulation of vascular tone with maturation.

In a study of the endothelium-dependent dilatation of coronary arteries in regard to maturation in the male pig, the mRNA of eNOS was lower in juvenile pigs than in adult pigs 24 Chatrath et al demonstrated that relaxation due to NO was greater in coronary arteries from adult compared with juvenile female pigs ${ }^{25}$ Moreover, relaxation was only significantly inhibited by cyclooxygenase in juveniles, suggesting that PGI2 was predominant in coronary dilatation in juvenile male pigs ${ }^{24}$ In the case of a human adipose cell study, eNOS expression was more prominent in adults than in children? 6

These studies suggest that substances related to vasodilatation were not constant throughout life. In females, coronary vasodilatation is largely affected by estrogen as indicated previously ${ }^{27}$ However, even in the presence of estrogen, the subjects of the non-genomic effects of estrogen may be modulated differently with age.

When seeking a therapeutic target associated with vasodilatation and vasoconstriction in different stages of the female life cycle, precise explanations of vasoactive substances are essential.

\section{Conclusions}

Oophorectomy brought about an increase in coronary vascular resistance. L-NNA exacerbated coronary vascular resistance in relation to maturation. It is suggested that the effect of estrogen on vascular dilatation in adolescent rats is largely dependent on a non-NO pathway, whereas adult rats are largely dependent on an NO pathway.

\section{Acknowledgments}

The authors are grateful to Mr. Avi Landau for his language consultation. This study was supported in part by a Grant-in-Aid for Scientific Research from the Japan Society for the Promotion of Science (grant B15390371) and a Grant-in-Aid for Female Health from the Akaeda Medical Research Foundation, Japan.

\section{References}

1. Wilson PW. Assessing coronary heart disease risk with traditional and novel risk factors. Clin Cardiol 2004; 27(6 Suppl 3): III-7-III-11.

2. Kannel WB, Abbott RD. Incidence and prognosis of unrecognized myocardial infarction: An update on the Framingham study. $N$ Engl $J$ Med 1984; 311:1144-1147.

3. Barrett-Connor E. Sex differences in coronary heart disease: Why are women so superior? The 1995 Ancel Keys Lecture. Circulation 1997; 95: $252-264$

4. Mendelsohn ME, Karas RH. Mechanisms of disease: The protective effects of estrogen on the cardiovascular system. N Engl J Med 1999; 340: $1801-1811$.

5. Stampfer MJ, Colditz GA, Willett WC, Manson JE, Rosner B, Speizer FE, et al. Postmenopausal estrogen therapy and cardiovascular disease. New Engl J Med 1991; 325: 756-762.

6. Bar J, Tepper R, Fuchs J, Pardo Y, Goldberger S, Ovadia J. The effect of estrogen replacement therapy on platelet aggregation and adenosine triphosphate release in postmenopausal women. Obstet
Gynecol 1993; 81: 261-264.

7. Beldekas JC, Smith B, Gerstenfeld LC, Sonenshein GE, Franzblau C. Effects of $17 \beta$-estradiol on the biosynthesis of collagen in cultured bovine aortic smooth muscle cells. Biochemistry 1981; 20: $2162-$ 2167.

8. Reckelhoff JF, Zhang H, Srivastava K. Gender differences in development of hypertension in spontaneously hypertensive rats: Role of the renin-angiotensin system. Hypertension 2000; 35: 480-483.

9. Reckelhoff JF. Gender differences in the regulation of blood pressure. Hypertension 2001; 37: 1199-1208.

10. Rifici VA, Khachadurian AK. The inhibition of low-density lipoprotein oxidation by 17- $\beta$ estradiol. Metabolism 1992; 41: 1110-1114.

11. Van der Mooren MJ, Mijatovic V, van Baal WM, Stehouwer CD. Hormone replacement therapy in postmenopausal women with specific risk factors for coronary artery disease. Maturitas 1998; 30: $27-36$.

12. Suwannaprapha P, Chaisri U, Riyong D, Maneerat Y. Improvement of function and morphology of tumor necrosis factor- $\alpha$ treated endothelial cells with 17- $\beta$ estradiol: A preliminary study for a feasible simple model for atherosclerosis. Circ J 2005; 69: 730-738.

13. Hayashi T, Fukuto JM, Ignarro LJ, Chaudhuri G. Basal release of nitric oxide from aortic rings is greater in female rabbits than in male rabbits: Implications for atherosclerosis. Proc Nat Acad Sci USA 1992; 89: 11259-11263.

14. Gorodeski GI, Yang T, Levy MN, Goldfarb J, Utian WH. Effects of estrogen in vivo on coronary vascular resistance in perfused rabbit hearts. Am J Physiol 1995; 269: R1333-R1338.

15. Koh KK. Effects of estrogen on the vascular wall: Vasomotor function and inflammation. Cardiovasc Res 2002; 55: 714-726.

16. Nakayama M, Yasue H, Yoshimura M, Shimasaki Y, Kugiyama K, Ogawa $\mathrm{H}$, et al. T-786 $\rightarrow \mathrm{C}$ mutation in the 5'-flanking region of the endothelial nitric oxide synthase gene is associated with coronary spasm. Circulation 1999; 99: 2864-2870.

17. Kobayashi K, Kouzuma R, Tsutsui M, Okazaki M, Tasaki H, Nakashima Y. Vasospastic angina in a 16-year-old female: Report of the youngest female patient and review of the literature. Circ J 2003; 67: 467-469.

18. Willis AP, Leffler CW. Endothelial NO and prostanoid involvement in newborn and juvenile pig pial arteriolar vasomotor responses. Am J Physiol Heart Circ Physiol 2001; 281: H2366-H2377.

19. Inazu N, Fujii T. Ovarian carbonyl reductase activity in rats at persistent oestrus. J Reprod Fertil 1996; 108: 123-130.

20. Liu MY, Hattori Y, Fukao M, Sato A, Sakuma I, Kanno M. Alterations in EDHF-mediated hyperpolarization and relaxation in mesenteric arteries of female rats in long-term deficiency of oestrogen and during oestrus cycle. Br J Pharmacol 2001; 132: 1035-1046.

21. Orshal JM, Khalil RA. Gender, sex hormones, and vascular tone. Am J Physiol Regul Integr Comp Physiol 2004; 286: R233-R249.

22. Geary GG, Buchholz JN, Pearce WJ. Maturation depresses mouse cerebrovascular tone through endothelium-dependent mechanisms. Am J Physiol Regul Integr Comp Physiol 2003; 284: R734-R741.

23. Sandow LS, Goto K, Rummery NM, Hill CE. Developmental changes in myoendothelial gap junction mediated vasodilator activity in the rat saphenous artery. J Physiol 2004; 556(Pt 3): 875-886.

24. Chatrath R, Ronningen KL, Severson SR, LaBreche P, Jayachandran M, Bracamonte MP, et al. Endotheliam-dependent responses in coronary arteries are changed with puberty in male pigs. Am J Physiol Heart Circ Physiol 2003; 285: H1168-H1176.

25. Chatrath R, Ronningen KL, LaBreche P, Severson SR, Jayachandran $\mathrm{M}$, Bracamonte MP, et al. Effect of puberty on coronary arteries from female pigs. J Appl Physiol 2003; 95: 1672-1680.

26. Knerr I, Schirl C, Horbach T, Stuppy A, Carbon R, Rascher W, et al. Maturation of the expression of adrenomedullin, endothelin- 1 and nitric oxide synthases in adipose tissues from childhood to adulthood. Int J Obesity 2005; 29: 275-280.

27. Case J, Davison CA. Estrogen alters relative contributions of nitric oxide and cyclooxygenase products to endothelium-dependent vasodilation. J Pharmacol Exp Ther 1999; 291: 524-530. 